\title{
ORIGINAL
}

ARTICLES

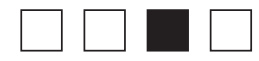

\section{Financial Impact of Universal Precepting in Family Medicine Residency Clinics}

Peter G. Harper, MD, MPH; Patricia Adam, MD; Mike Wootten, MD; Angela Smithson, MD, MPH; Casey Martin, MD; Samantha Friedrichsen, MPH; Andrew M. Pattock; David J. Satin, MD

\begin{abstract}
BACKGROUND AND OBJECTIVES: Precepting methods have significant impact on the financial viability of family medicine residency programs. Following an adverse event, four University of Minnesota Family Medicine residency clinics moved from using Medicare's Primary Care Exception (PCE) and licensure precepting (LP) to a "universal precepting" method in which preceptors see every patient face to face. Variation in the implementation of universal precepting created a natural experiment of its financial impact.
\end{abstract}

METHODS: Universal precepting was implemented in October 2013 across four residency programs. Billing codes were measured 1 year before and 2.5 years after implementation by clinic and residency year.

RESULTS: There were significant financial differences between clinics based on original precepting method and implementation quality of universal precepting. The clinic moving from PCE to universal precepting with excellent implementation increased higher-level billing (99214) by $8 \%-10 \%$. Clinics moving from LP demonstrated wide variation ranging from an $18 \%$ increase to a $13 \%$ decrease, consistent with the implementation quality.

CONCLUSIONS: Clinics transitioning from PCE to universal precepting can see a significant increase in 99214 billing. Clinics transitioning from LP to universal precepting are at significant financial risk if poorly implemented, but may see increased 99214 billing with effective implementation. This suggests that both implementation quality and original precepting method impact 99214 billing rates when transitioning to universal precepting.

(Fam Med. 2020;52(1):24-30.)

doi: 10.22454/FamMed.2019.690858

Published Online First November 4, 2019

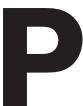
recepting residents in their continuity clinic is a core component of resident education, patient safety, quality care, and the financial viability of residency clinics. ${ }^{1,2}$ Family medicine residency clinics typically bill below nationally recognized benchmarks, ${ }^{1}$ and residents have been shown to bill lower evaluation and management (E\&M) codes than faculty for similar clinic
There are two commonly used precepting methods: Medicare's Primary Care Exception (PCE),${ }^{16}$ and a method we call licensure precepting (LP). The PCE requires preceptors to see all postgraduate year-1 (PGY1) patients face to face during the first 6 months of residency. Thereafter, face-to-face precepting is required only for higher-level billing $(99214,99215)$, which is a surrogate measure for complexity. ${ }^{17}$ Although the PCE is a Medicare regulation, many residencies apply it to all insurance types. Doing this can result in a substantial loss of revenue- up to $\$ 57,000$ per year in one study. ${ }^{18}$ The mechanism for this lost revenue is unclear. It would be concerning from a regulatory perspective if this resulted from residents downcoding higher level visits to 99213 because the faculty missed seeing the patient face to face.

LP is based on the licensure status of the resident. For this method to work, the community-based clinic must be able to bill under the licensed resident (and not their preceptor). With LP, all cases require face-to-face precepting until the resident is licensed in their PGY-2 year. Thereafter, licensed residents can see patients without face-to-face precepting medical students ${ }^{11-13}$ and improving residency preceptor efficacy. ${ }^{14,15}$ There is no literature on the financial impact of different precepting methods.
From the Department of Family Medicine and Community Health (Drs Harper, Adam, Wootten, Smithson, Martin, and Satin, and Ms Friedrichsen), University of Minnesota Medical School, Minneapolis, MN (Mr Pattock). 
precepting unless they or the patient requests the preceptor see the patient. For cases with higher complexity, this allows for commensurate higher-level billing under the resident's license without waiting for the preceptor to be available, but there is no documentation in the literature about this method.

Prior to the study period, three of the four residency clinics at the University of Minnesota's Department of Family Medicine and Community Health had been using LP for many years and one hospitalbased clinic was using PCE. Following an adverse patient outcome, the institution's Compliance and Risk Management Committee mandated increased supervision of all family medicine residents, going beyond both the PCE and LP standards. In response, the Department transitioned to a method we call "universal precepting."

With universal precepting the preceptor sees all patients face to face regardless of resident year, licensure status, patient insurance, complexity, or acuity. This may happen at any point in the visit. The ensuing preceptor-resident discussion of each patient always includes medical decision-making. This cognitive work constitutes the key portion of a family medicine E\&M visit. Because the preceptor has seen the patient, appropriate higher-level billing can occur provided there is medical necessity for complex medical decision-making. Nevertheless, the preceptor-resident discussion may result in the preceptor returning to the exam room to clarify elements of history or physical exam needed for sound medical decision-making.

The change to universal precepting was not uniformly embraced by all clinics. Variability in implementation of universal precepting, and the baseline difference in clinic precepting method (PCE vs LP), created a natural experiment to assess the financial impact of the precepting change. In this paper we explore and compare the financial impact of universal precepting implementation at four family medicine residency clinics over 4 years based on original precepting method and implementation quality.

\section{Methods}

\section{Setting}

Four University of Minnesota Family Medicine residency clinics participated in the study. All clinics are located in urban, underserved communities. Over $80 \%$ of patients are on government insurance programs and over $30 \%$ require interpreters. There are a total of 90 residents and 41 core faculty across the four clinics with very little preceptor and no resident crossover between clinics.

There is an established, joint operational infrastructure of meetings and site visits to manage the four residency clinics. At two collaborative work meetings each month (one operational and one strategic) the clinic leadership teams review clinic metrics (quality, financials, access), and plan initiative implementations such as universal precepting. In addition, the department medical director rounds with each clinic leadership team monthly at their clinic to witness the care being provided and assess initiative implementation.

\section{Precepting Methods}

Prior to the study, Clinic A used the PCE precepting method, and Clinics B, C, and D used the LP method. In this study, all four clinics transitioned to universal precepting. The faculty-patient encounter for universal precepting may happen at any point in the visit such as immediately following the rooming process, during the visit with the resident, or after the resident has seen and discussed the patient. When needed, the preceptor returns to the exam room for education, clinical questions, or to clarify elements of history or physical exam needed for sound medical decision-making.

\section{Coding Review}

The practice organization's coding department manages the billing and coding for the four clinics. Coders review $100 \%$ of all faculty and resident notes to assure accurate and justified coding, providing clinic leadership with regular billing reports. They enforced universal precepting by ensuring a face-to-face preceptor note was present even for licensed residents. Universal precepting rules were applied to all insurers.

\section{Implementation}

Between January and July 2013, the four clinic leadership teams, the department medical director, and operations leader together developed the universal precepting guidelines. The local clinic leadership was responsible for implementation by October 2013. Universal precepting was discussed regularly at department meetings and the department medical director and administrative team followed the four clinics' implementation of universal precepting.

\section{Implementation Evaluation}

The authors (PH, DS) rated implementation quality based on the timing and number of the following five implementation elements: preceptor expectations (Table 1), preceptor standard work (Table 1), decreasing the ratio of preceptors from 4:1 to 3:1 to accommodate the extra precepting work, monitoring adherence to the process, and education of preceptors and residents.

These five implementation elements were developed and monitored blinded to the financial data. The presence and timing of these elements was assessed using clinics' self-reports and on-site observations by authors (P.H., D.S.). The elements were bundled together after reviewing the financial data and were used to classify the clinic implementation quality as excellent, good, fair, and poor.

\section{Data Collection and Analysis}

The primary outcome was change in 99214 E\&M billing. We chose E\&M codes to isolate billing differences most sensitive to preceptor-resident behavior. Billing codes 99211, 99212, and 99215 were excluded as these 
Table 1: Preceptor Expectations and Standard Work-Two Elements of the Clinic Implementation Quality Rating

\section{Preceptor Expectations}

1. Preceptor sees all patients sometime during the visit.

2. Preceptor and resident discuss each case.

3. Preceptor returns to the exam room for education, clinical questions, or to clarify elements of history or physical exam needed for sound medical decision-making.

4. Preceptor ensures appropriate billing based on the patient's medical complexity.

5. Preceptors should not expect to get other work done (eg, email, research) while precepting.

\section{Preceptor Standard Work}

1. Review schedule and concerns with residents before clinic.

2. Go to the exam room when alerted by rooming staff.

3. Review vital signs for any abnormalities.

4. Greet patient. Explain role as attending physician.

5. Assess patient for signs of serious illness.

6. Review reason for visit and other needs (eg, forms).

7. Alert resident of abnormal vital signs or potential issues in visit.

8. Discuss case with resident with particular attention to medical decision-making, follow-up plans, and level of service.

9. Return to the exam room for education, clinical questions, or to clarify elements of history or physical exam needed for sound medical decision-making.

10. Write and sign preceptor attestation.

11. Review and final sign completed resident notes.

were collectively billed less than 5\% of the time and rates remained unchanged in all phases of the study. Billing data was collected for each provider type (PGY-1, PGY-2, PGY-3, faculty) from July 2012 to June 2016.

The 99214 billing code rate was defined as "the monthly percentage of established patient E\&M codes per provider type that were 99214." Although a 99213 billing code rate was similarly calculated, it represented a redundant mirror image of the 99214 rate (ie, when 99214 increased by $10 \%, 99213$ decreased by $10 \%$ ). We used analysis of covariance models to compare the billing code rates per month in three different time phases: preimplementation-before universal precepting (July 2012-July 2013); postimplementation - the first year after universal precepting (November 2013-December 2014); and maintenance phase-an 18-month period (January 2015-June 2016) following the postimplementation phase. We further conducted a subanalysis, splitting the maintenance phase into the first 6 months (January 2015-June 2015) and the latter 12 months (July 2015-June 2016), deemed "maintenance phase 2." All results were adjusted for faculty billing rates, assuming any changes in these rates represent secular trends.
We used SAS v.9.4 (SAS Institute Inc, Cary, NC) for analyses, and we considered $P$ values <.05 to be statistically significant. The University of Minnesota Institutional Review Board reviewed this study and determined it not to be human subjects research.

\section{Results}

The four clinics transitioned variably to universal precepting by October 2013. The implementation quality was based on the timing and number of implementation elements, and was classified as excellent, good, fair, or poor (Table 2). Clinic A with PCE prior to universal precepting had excellent implementation with all five process elements. Of the three clinics with LP, Clinic B had good implementation with most elements implemented in late postimplementation phase. Clinics $\mathrm{C}$ and $\mathrm{D}$ had fair and poor implementation, respectively. Clinic C implemented elements in the late maintenance phase, and Clinic D implemented no elements.

The 99214 billing code rates were calculated for each clinic by provider type (PGY-1, -2, -3, faculty) and compared preimplementation to postimplementation and maintenance phases (Table 3). Clinic A, moving from PCE to universal precepting with excellent implementation, had an $8 \%-10 \%$ increase in higher-level billing (99214). Clinics transitioning from LP demonstrated wide variations, ranging from an $18 \%$ increase to a $13 \%$ decrease in 99214 billing, consistent with the implementation quality.

Clinic A (excellent implementation) precepted based on the PCE prior to universal precepting. PGY1 residents did not have a change in billing. PGY-2 residents increased 99214 billing by $11 \%$ from preimplementation to postimplementation (51\% to $62 \%, P<.0065)$ and sustained this increase throughout the maintenance phase. PGY-3 residents increased their pre to postimplementation 99214 billing by $4 \%$, but had an $8 \%$ total increase from postimplementation to maintenance phase (56\% to $64 \%, P<.0009$ ).

Clinic B (good implementation) precepted based on LP prior to universal precepting. Following an initial drop, PGY-1 and PGY-2 residents ultimately had a $5 \%$ and $11 \%$ increase, respectively, from preimplementation to maintenance phase (61\% to $66 \%, P=.0117$ and $64 \%$ to $75 \%, P<.0001)$. PGY-3 residents increased their 99214 billing during each phase, ultimately by $18 \%$ from 
Table 2: Clinic Implementation Quality Rating by Timing and Number of Implementation Elements

\begin{tabular}{|l|c|c|c|c|l|}
\hline & $\begin{array}{c}\text { Original } \\
\text { Precepting } \\
\text { Method }\end{array}$ & $\begin{array}{c}\text { Implementation } \\
\text { Quality Rating }\end{array}$ & $\begin{array}{c}\text { Elements Present } \\
\text { in Implementation } \\
\text { Phase }\end{array}$ & $\begin{array}{c}\text { Elements Present } \\
\text { in Maintenance } \\
\text { Phase }\end{array}$ & \multicolumn{1}{|c|}{ Elements Implemented } \\
\hline Clinic A & PCE & Excellent & Yes & Yes & $\begin{array}{l}\text { 1. Preceptor expectations } \\
\text { 2. Preceptor standard work } \\
\text { 3. Education } \\
\text { 4. Audit system } \\
\text { 5. Preceptor ratio 3:1 }\end{array}$ \\
\hline Clinic B & LP & Good & Limited & Yes & $\begin{array}{l}\text { 1. Preceptor expectations } \\
\text { 2. Education } \\
\text { 3. Audit system }\end{array}$ \\
\hline Clinic C & LP & Fair & No & Yes - late & $\begin{array}{l}\text { 1. Preceptor expectations } \\
\text { 2. Education } \\
\text { 3. Preceptor ratio 3:1 }\end{array}$ \\
\hline Clinic D & LP & Poor & No & No & None \\
\hline
\end{tabular}

Abbreviations: PCE, Primary care exception; LP, licensure precepting.

preimplementation to maintenance phase $(57 \%$ to $75 \%, P<.0001)$.

Clinic C (fair implementation) precepted based on LP prior to universal precepting. There were no statistically significant changes in 99214 billing for any resident level during the postimplementation or maintenance phase. Analysis of the differences in 99214 billing from the preimplementation phase to "maintenance phase 2 " revealed a statistically significant $9 \%$ increase in the PGY-2 cohort (53\% to $62 \%, P=.0049$ ) with PGY-1 and PGY-3 cohorts remaining unchanged (Table 4).

Clinic D (poor implementation) precepted based on LP prior to universal precepting. PGY-1 residents had a statistically significant 99214 billing decrease of $12 \%$ in the postimplementation phase (53\% to $41 \%$, $P=.0046)$. They then rebounded back to preimplementation levels during the maintenance phase. G2 resident levels were unchanged throughout the study. PGY-3 residents had a $17 \%$ decrease in the postimplementation phase (63\% to $46 \%, P<.0001$ ) and ultimately retained a $13 \%$ decrease in the maintenance phase. The maintenance phase 2 subanalysis confirmed there were no late trends (Table 4).

\section{Discussion}

Transitioning from the Primary Care Exception (PCE) or licensure precepting (LP) to universal precepting was accompanied by substantial changes in resident billing patterns. Although we hypothesized that the original precepting method would be the main determinant of billing outcome differences, the data suggest that implementation quality may also have a significant impact.

Clinics transitioning from PCE to universal precepting had the most to gain financially. Because the PCE requires preceptors to see all patients with higher complexity, universal precepting fulfilled this regulatory mandate while simultaneously removing the potential for inappropriate downcoding due to missed preceptor-patient face-to-face visits. The data from Clinic A, which transitioned from PCE, does show statistically significant increases in higher-level billing. Clinic A had excellent implementation, which may be a contributing factor for increased higher-level billing.

Clinics transitioning from LP to universal precepting had the most to lose financially if not implemented fully. In LP clinics, preceptors were accustomed to only seeing patients for clinical reasons, since residents were able to independently bill higher-level codes. But in transitioning to universal precepting, patients would now need face-to-face precepting or the visit would be downcoded. The implementation quality at each of these three clinics varied widely and there were vastly different financial outcomes.

Clinic D, with poor implementation quality, had a statistically significant loss of revenue, which was predicted. Clinics B and C had imperfect transitions, implementing elements in the late implementation phase and late maintenance phase, respectively. Each clinic saw an increase in high-level billing following these interventions. This suggests that implementation quality together with the original precepting method influence billing outcomes.

Still, neither the original precepting method nor implementation quality can completely explain how Clinics B and C eventually exceeded their LP baseline. We hypothesize that effective implementation of universal precepting may have had a Hawthorne effect and/or fostered new cultural norms of engaged precepting. This is supported by the unexpected increases above baseline after the implementation of several elements such as defined preceptor expectations and 3:1 preceptor ratios.

The data also suggests that family medicine residencies may be missing legitimate revenue. The data 
Table 3: Average Monthly 99214 Billing in Preimplementation, Postimplementation, and Maintenance Phases

\begin{tabular}{|c|c|c|c|c|c|c|c|c|}
\hline & & 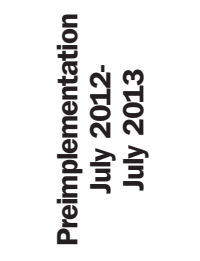 & 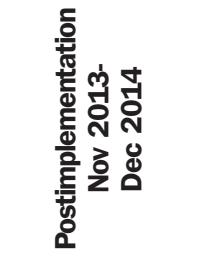 & 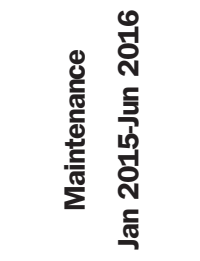 & 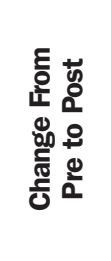 & $\frac{\sqrt{0}}{\frac{\pi}{20}}$ & 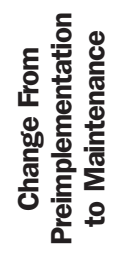 & $\frac{71}{\frac{7}{\pi}}$ \\
\hline \multicolumn{9}{|c|}{ Clinic A (PCE; Excellent Implementation) } \\
\hline $\begin{array}{l}\mathrm{N} \text { (All } \\
\text { time pe }\end{array}$ & $\begin{array}{l}\text { billed for } \\
\text { all codes) }\end{array}$ & $\begin{array}{c}\text { PGY1 (650) } \\
\text { PGY2 (1,715) } \\
\text { PGY3 (751) }\end{array}$ & $\begin{array}{c}\text { PGY1 }(867) \\
\text { PGY2 }(2,416) \\
\text { PGY3 }(2983)\end{array}$ & $\begin{array}{l}\text { PGY1 }(1,130) \\
\text { PGY2 }(3,669) \\
\text { PGY3 }(3,847)\end{array}$ & & & & \\
\hline PGY1 & 99214 & $59 \% \pm 3$ & $64 \% \pm 3$ & $63 \% \pm 2$ & $5 \% \pm 4$ & .2469 & $4 \% \pm 5$ & .3552 \\
\hline PGY2 & 99214 & $51 \% \pm 3$ & $62 \% \pm 2$ & $62 \% \pm 2$ & $11 \% \pm 3$ & $.0033 *$ & $10 \% \pm 4$ & $.0065^{*}$ \\
\hline PGY3 & 99214 & $56 \% \pm 2$ & $60 \% \pm 1$ & $64 \% \pm 1$ & $4 \% \pm 2$ & .0549 & $8 \% \pm 2$ & $.0009 *$ \\
\hline \multicolumn{9}{|c|}{ Clinic B (LP; Good Implementation) } \\
\hline $\begin{array}{l}\mathrm{N}(\text { All } \\
\text { time pe }\end{array}$ & $\begin{array}{l}\text { billed for } \\
\text { all codes) }\end{array}$ & $\begin{array}{c}\text { PGY1 }(4,021) \\
\text { PGY2 }(3,215) \\
\text { PGY3 }(701)\end{array}$ & $\begin{array}{l}\text { PGY1 }(1,868) \\
\text { PGY2 }(4,905) \\
\text { PGY3 }(3,507)\end{array}$ & $\begin{array}{l}\text { PGY1 }(2,496) \\
\text { PGY2 }(4,677) \\
\text { PGY3 }(8,320)\end{array}$ & & & & \\
\hline PGY1 & 99214 & $61 \% \pm 1$ & $56 \% \pm 2$ & $66 \% \pm 1$ & $-5 \% \pm 2$ & .0511 & $5 \% \pm 2$ & $.0117 *$ \\
\hline PGY2 & 99214 & $64 \% \pm 1$ & $60 \% \pm 2$ & $75 \% \pm 1$ & $-3 \% \pm 2$ & .1594 & $11 \% \pm 2$ & $<.0001 *$ \\
\hline PGY3 & 99214 & $57 \% \pm 2$ & $62 \% \pm 2$ & $75 \% \pm 2$ & $5 \% \pm 3$ & $.0488 *$ & $18 \% \pm 2$ & $<.0001 *$ \\
\hline \multicolumn{9}{|c|}{ Clinic C (LP; Fair Implementation) } \\
\hline $\begin{array}{l}\mathrm{N} \text { (All } \\
\text { time pe }\end{array}$ & $\begin{array}{l}\text { billed for } \\
\text { all codes) }\end{array}$ & $\begin{array}{l}\text { PGY1 }(1,350) \\
\text { PGY2 }(2,767) \\
\text { PGY3 }(2,883)\end{array}$ & $\begin{array}{l}\text { PGY1 }(1,227) \\
\text { PGY2 }(3,069) \\
\text { PGY3 }(3,649)\end{array}$ & $\begin{array}{l}\text { PGY1 }(1,799) \\
\text { PGY2 }(3,449) \\
\text { PGY3 }(4,331)\end{array}$ & & & & \\
\hline PGY1 & 99214 & $58 \% \pm 2$ & $62 \% \pm 2$ & $59 \% \pm 2$ & $5 \% \pm 2$ & .0709 & $1 \% \pm 2$ & .6855 \\
\hline PGY2 & 99214 & $53 \% \pm 2$ & $57 \% \pm 2$ & $57 \% \pm 2$ & $4 \% \pm 3$ & .2159 & $3 \% \pm 3$ & .2678 \\
\hline PGY3 & 99214 & $58 \% \pm 2$ & $56 \% \pm 2$ & $58 \% \pm 2$ & $-2 \% \pm 3$ & .4428 & $0 \% \pm 3$ & .8694 \\
\hline \multicolumn{9}{|c|}{ Clinic D (LP; Poor Implementation) } \\
\hline $\begin{array}{l}\mathrm{N} \text { (All } \\
\text { time pe }\end{array}$ & $\begin{array}{l}\text { billed for } \\
\text { all codes) }\end{array}$ & $\begin{array}{c}\text { PGY1 (763) } \\
\text { PGY2 }(1,633) \\
\text { PGY3 }(3,130)\end{array}$ & $\begin{array}{c}\text { PGY1 }(321) \\
\text { PGY2 }(1,576) \\
\text { PGY3 }(1,531)\end{array}$ & $\begin{array}{c}\text { PGY1 }(522) \\
\text { PGY2 }(2,143) \\
\text { PGY3 }(2,852)\end{array}$ & & & & \\
\hline PGY1 & 99214 & $53 \% \pm 3$ & $41 \% \pm 3$ & $56 \% \pm 2$ & $-12 \% \pm 4$ & $.0046^{*}$ & $4 \% \pm 4$ & .3115 \\
\hline PGY2 & 99214 & $50 \% \pm 3$ & $52 \% \pm 3$ & $53 \% \pm 2$ & $2 \% \pm 4$ & .7055 & $3 \% \pm 4$ & .4382 \\
\hline PGY3 & 99214 & $63 \% \pm 2$ & $46 \% \pm 2$ & $49 \% \pm 2$ & $-17 \% \pm 2$ & $<.0001^{*}$ & $-13 \% \pm 2$ & $<.0001^{*}$ \\
\hline
\end{tabular}

Abbreviations: PCE, Primary care exception; LP, licensure precepting.

${ }^{1} P$ values from ANCOVAs, adjusted for faculty billing code monthly rates.

$* P<.05$.

Values are: mean $\% \pm \mathrm{SE}$, or mean $\%$ difference $\pm \mathrm{SE}$.

Shaded cells indicate change in the negative direction.

reveals 99214 billing in the $50 \%$ $60 \%$ range preimplementation and even higher in the maintenance phase. By comparison, 99214 billing were in the $13 \%-25 \%$ range for multiple residency practices in the Pacific Northwest. ${ }^{18}$ This is a significant differential and could raise concerns about miscoding or fraud.
Reassuringly, there was $100 \%$ coding review by our billing department. Therefore, it raises questions about whether family medicine residency programs may be missing legitimate revenue due to differences in coding, application of PCE across all payers, ${ }^{18}$ population complexity, or precepting methods.

\section{Limitations / Future Directions}

A major limitation in this study is that it was a natural experiment that did not control for potential confounding factors. However, the clinics were within one health care system and operated by a central leadership team, so they are structurally more alike than different. Nonetheless, 
Table 4: Change in Average Monthly 99214 Billing From Preimplementation Phase to Maintenance Phase 2

\begin{tabular}{|c|c|c|c|c|c|}
\hline & & $\begin{array}{l}\text { Preimplementation: } \\
\text { July 2012-July } 2013\end{array}$ & $\begin{array}{l}\text { Maintenance Phase 2: } \\
\text { July 2015-June } 2016\end{array}$ & $\begin{array}{c}\text { Change From } \\
\text { Preimplementation } \\
\text { to Maintenance } \\
\text { Phase } 2\end{array}$ & $P$ Value $^{1}$ \\
\hline \multicolumn{6}{|c|}{ Clinic C } \\
\hline \multicolumn{2}{|c|}{$\mathrm{N}$ (all visits billed for time period, all codes) } & $\begin{array}{l}\text { PGY1 }(1,350) \\
\text { PGY2 }(2,767) \\
\text { PGY3 }(2,883)\end{array}$ & $\begin{array}{l}\text { PGY1 }(1,225) \\
\text { PGY2 }(2,429) \\
\text { PGY3 }(2,918)\end{array}$ & & \\
\hline PGY1 & 99214 & $58 \% \pm 2$ & $56 \% \pm 2$ & $-2 \% \pm 3$ & .5567 \\
\hline PGY2 & 99214 & $53 \% \pm 2$ & $62 \% \pm 2$ & $9 \% \pm 3$ & $.0049 *$ \\
\hline PGY3 & 99214 & $58 \% \pm 2$ & $61 \% \pm 2$ & $3 \% \pm 3$ & .2973 \\
\hline \multicolumn{6}{|c|}{ Clinic D } \\
\hline \multicolumn{2}{|c|}{$\mathrm{N}$ (all visits billed for time period, all codes) } & $\begin{array}{l}\text { PGY1 (763) } \\
\text { PGY2 (1,633) } \\
\text { PGY3 }(3,130)\end{array}$ & $\begin{array}{c}\text { PGY1 (339) } \\
\text { PGY2 (1,688) } \\
\text { PGY3 }(1,968)\end{array}$ & & \\
\hline PGY1 & 99214 & $53 \% \pm 3$ & $57 \% \pm 3$ & $4 \% \pm 4$ & .3062 \\
\hline PGY2 & 99214 & $50 \% \pm 3$ & $56 \% \pm 3$ & $6 \% \pm 4$ & .1320 \\
\hline PGY3 & 99214 & $63 \% \pm 2$ & $50 \% \pm 2$ & $-13 \% \pm 2$ & $<.0001 *$ \\
\hline
\end{tabular}

${ }^{1} P$ values from ANCOVAs, adjusted for faculty billing code monthly rates.

$* P<.05$.

Values are: mean $\% \pm \mathrm{SE}$ or mean $\%$ difference $\pm \mathrm{SE}$.

Shaded cells indicate change in the negative direction.

each clinic has its own culture that may have influenced the results.

Another limitation is the potential for bias in our implementation quality rating system. Although the elements implemented were developed and monitored blinded to the financial data, bundling them to form an overall implementation quality rating occurred after reviewing the financial data. This may have potentially oversimplified the relationship between financial outcomes and overall implementation quality rating.

It is difficult to predict the effect of the new Centers for Medicare and Medicaid Services (CMS) billing regulations for E\&M services effective in 2021. Under the new regulations there will be a single, blended payment rate for E\&M office visit levels 2 through 4 - one rate for new patient visits, and one rate for established patient visits. ${ }^{19}$ There will also be additional add-on codes to differentiate complexity. This could change the calculus of precepting and finances. These changes may rekindle debates from years ago that resulted in the Primary Care Exception and the resulting "Unintended Consequences." ${ }^{20}$ Nonetheless, universal precepting maximizes accurate coding and places programs in the most flexible position to navigate changes in CMS precepting regulations.

\section{Conclusions}

Clinics transitioning from PCE to universal precepting can see a significant increase in 99214 billing. Clinics transitioning from LP to universal precepting are at significant financial risk if poorly implemented, but may see increased 99214 billing with effective implementation. This suggests that both implementation quality and original precepting method impact 99214 billing rates when transitioning to universal precepting.

CORRESPONDING AUTHOR: Address correspondence to Dr Peter G. Harper, University of Minnesota Department of Family Medicine and Community Health, 2020 E. 28th St, Minneapolis, MN 55407. 612-333-0774. Fax: 612333-1986.harpe006@umn.edu.

\section{References}

1. Evans DV, Cawse-Lucas J, Ruiz DR, Allcut EA, Andrilla CH, Norris T. Family medicine resident billing and lost revenue: a regional cross-sectional study. Fam Med. 2015;47(3):175181.

2. Al Achkar M, Kengeri-Srikantiah S, Yamane BM, Villasmil J, Busha ME, Gebke KB. Billing by residents and attending physicians in family medicine: the effects of the provider, patient, and visit factors. BMC Med Educ. 2018;18(1):136.

3. Kapa S, Beckman TJ, Cha SS, et al. A reliable billing method for internal medicine resident clinics: financial implications for an academic medical center. J Grad Med Educ. 2010;2(2):181-187.

4. Hirsh JM, Collier DH, Boyle DJ, Gardner EM. A concise evaluation and management curriculum for physicians in training improved billing at an outpatient academic rheumatology clinic. J Clin Rheumatol. 2010;16(3):148-150.

5. Waugh JL. Education in medical billing benefits both neurology trainees and academic departments. Neurology. 2014;83(20):1856-1861.

6. Gala RB, Chiang S. The impact of a documentation and coding curriculum in an obstetrics and gynecology continuity clinic. Ochsner J. 2012;12(4):354-358.

7. Dezfuli B, Smith JL. Level of billing as a function of resident documentation and orthopedic subspecialty at an academic multispecialty orthopedic surgery practice. Orthopedics. 2012;35(11):e1655-e1658. 
8. Ghaderi KF, Schmidt ST, Drolet BC. Coding and billing in surgical education: a systemsbased practice education program. J Surg Educ. 2017;74(2):199-202.

9. Benke JR, Lin SY, Ishman SL. Directed educational training improves coding and billing skills for residents. Int J Pediatr Otorhinolaryngol. 2013;77(3):399-401.

10. Nguyen D, O'Mara H, Powell R. Improving coding accuracy in an academic practice. US Army Med Dep J. 2017 Jul-Sep;(2-17):95-98.

11. Ward A, McComb S. Precepting: A literature review. J Prof Nurs. 2017;33(5):314-325.

12. Ignoffo R, Chan L, Knapp K, et al. Efficient and effective precepting of pharmacy students in acute and ambulatory care rotations: A Delphi expert panel study. Am J Health Syst Pharm. 2017;74(19):1570-1578.

13. Power DV, Rosenbaum ME, Hanson L, et al. Precepting Medical Students in the Patient's Presence: An Educational Randomized Trial in Family Medicine Clinic. Fam Med. 2017;49(2):97-105
14. Lillich DW, Mace K, Goodell M, Kinnee C. Active precepting in the residency clinic: a pilot study of a new model. Fam Med. 2005;37(3):205-210.

15. Jones HC. An observational study of precepting encounters in a family practice residency program. Fam Med. 2002;34(6):441-444.

16. Tobin DG, Doolittle BR, Ellman MS, Ruser CB, Brienza RS, Genao I. Modifying the Primary Care Exception Rule to Require CompetencyBased Assessment. Acad Med. 2017;92(3):331334.

17. US Department of Health and Human Services CMS. Guidelines for teaching physicians, interns, and residents. Washington, DC: Medicare Learning Network; 2017. https://www.cms. gov/Outreach-and-Education/Medicare-Learning-Network-MLN/MLNProducts/Downloads/ Teaching-Physicians-Fact-Sheet-ICN006437. pdf. Accessed Feb 1, 2018.

18. Cawse-Lucas J, Evans DV, Ruiz DR, et al. Impact of the Primary Care Exception on Family Medicine Resident Coding. Fam Med. 2016;48(3):175-179
19. US Department of Health and Human Services CMS. Accessed June 3, 2019.. Medicare Program; Revisions to Payment Policies Under the Physician Fee Schedule and Other Revisions to Part B for CY 2019. Federal Register. pg. 59636-59638. Published November 23, 2018. https://federalregister.gov/d/2018-24170. Accessed June 3, 2019.

20. Saultz J. Unintended consequences. Fam Med 2016;48(3):173-174. 